\title{
Diet and body temperature in mammals and birds
}

\author{
Andrew Clarke $\mathrm{e}^{1,2 *}$ and Mary I. O’Connor ${ }^{3}$ \\ ${ }^{1}$ British Antarctic Survey, High Cross, Madingley Road, Cambridge CB3 OET, UK \\ ${ }^{2}$ School of Environmental Sciences, University of East Anglia, Norwich Research Park, \\ Norwich NR4 7TJ, UK \\ ${ }^{3}$ Department of Zoology, University of British Colombia, 2329 West Mall, Vancouver, B.C., \\ CanadaV6T 1Z4
}

* Correspondence: Andrew Clarke E-mail: accl@bas.ac.uk Mary O’Connor E-mail: oconnor@zoology.ubc.ca

Keywords: Energetics, macroecology, macrophysiology, metabolism, mammal, reptile, bird, fish, endothermy

\section{ABSTRACT}

Aim We test the hypothesis that endotherm body temperature varies with diet.

Location Global terrestrial ecosystems

Methods We compile data from the literature on diet and body temperature in mammals and birds. We analyse these and demonstrate global macrophysiological patterns.

Results In mammals, carnivores overall have a lower mean body temperature $\left(T_{b}\right)$ than either herbivores or omnivores. However within carnivores, those taking vertebrate prey have a higher mean $T_{b}$ than predators of invertebrates. Among herbivores, species eating grass, leaves or seeds have the highest mean $T_{b}$, those taking fruit an intermediate mean $T_{b}$ and those taking flowers or nectar the lowest mean $\mathrm{T}_{\mathrm{b}}$. These patterns are robust to the influence of body mass and phylogenetic non-independence. In birds the relationship between $T_{b}$ and diet is complicated by a significant inverse relationship between body mass and $\mathrm{T}_{\mathrm{b}}$ and strong dietary niche conservation within lineages. After allowing for body mass, herbivores show an identical qualitative pattern to mammals, whereas carnivores show the opposite trend to mammals: those taking invertebrate prey have a higher mean $T_{b}$ than those taking vertebrates.

Main conclusions There is a relationship between diet and $T_{b}$ in mammals that is statistically and phylogenetically robust. Published studies show that in reptiles and fish herbivory is largely confined to species that can maintain a relatively high $\mathrm{T}_{\mathrm{b}}$ either through living in warm environments or through behavioural thermoregulation. We therefore propose a general relationship for all vertebrates: herbivory requires a warmer body than carnivory. Basal metabolic rate (BMR) will then be higher in herbivores because of the universal relationship between $B M R$ and $T_{b}$, together with the higher maintenance costs of their longer guts. We suggest that the evolution of endothermy was a key factor in the widespread incidence of herbivory in mammals. 


\section{INTRODUCTION}

It has been known for a long time that the basal metabolic rate (BMR) of mammals is correlated with their diet (McNab 1992, 2008), and similar patterns have also been detected in field metabolic rate (Speakman 2000).

Recently Clarke et al. (2010) re-examined the relationship between BMR and body mass, incorporating body temperature, $\mathrm{T}_{\mathrm{b}}$, in the statistical model. This confirmed previous suggestions of a curvilinear relationship between body mass and BMR (Heusener 1985; Lovegrove 2003; Glazier 2005) and also the marked dependence of BMR on body temperature (White \& Seymour 2003, 2004, 2005). Interestingly, the well established relationship between BMR and diet (McNab 1992, 2008) vanished when body temperature was included in the model (Clarke et al. 2010). The cause was a strong covariance between body temperature and diet, and this suggested the possibility that the underlying relationship was between diet and body temperature, with BMR responding through its dependence on $T_{b}$.

Here we explore the relationship between diet and body temperature in mammals in more detail. Specifically we test the hypothesis that herbivory requires a higher body temperature than carnivory. We extend the analysis to include birds, compare the results with published studies of reptiles, amphibians and fish, and propose a general macrophysiological relationship for all vertebrates.

\section{METHODS}

The data sets comprised body mass, body temperature and diet. The data for body temperature $\left(\mathrm{T}_{\mathrm{b}}\right)$ came from previous studies of the scaling of body temperature (Clarke \& Rothery 2008) and BMR (Clarke et al.2010).

Data for diet and the mean environmental temperature within the range for each mammalian species in our data set were downloaded from the PanTheria database (Jones et al. 2009). The dietary information for birds was taken from del Hoyo et al. (1992-2011). In many cases a given species feeds on more than one class of item; where this was the case then the diet class assigned was based on the most frequent item(s), as determined from quantitative dietary analyses.

The differing chemical composition of plant leaves, fruits and animal tissue led Chivers \& Hladik (1980) to propose an alternative dietary classification for primates: faunivory (carnivory), frugivory and foliovory. This classification was based on the adaptations of the gut necessary to digest and absorb the different diets (see also Karasov et al. 2011). We extended this classification to all endotherms, adding an extra category (granivory) for those species eating seeds. We also split the carnivore category to distinguish species taking invertebrates from those preying principally on vertebrates.

Because of the potential errors introduced by the assignment of taxa with a broad dietary niche to a single food category, an alternative classification based on broader trophic levels was also used. For mammals the classification of trophic levels in the PanTheria database was used without modification. For birds, species were classified as omnivores when their diet contained more than $30 \%$ of both animal and vegetable matter. Where dietary analysis was non-quantitative (presence/absence data only) then the assignment was based on 
subjective judgement. To check the robustness of ecological conclusions following from statistical analysis based on this initial classification (Trophic Level 1), a stricter trophic level classification was used, whereby some taxa classified as carnivores or herbivores, because a majority of their food was animal or plant material, were reclassified as omnivores (Trophic Level 2). As an example of the differences between these two classifications, thrushes and finches were classified as carnivores or herbivores respectively in the first, but as omnivores in the second.

There were data for 426 species of mammal and 414 species of bird (with less detailed dietary information available for a further 71 bird taxa). The species-level taxonomy and assignment of taxa to families and orders used here followed Wilson \& Reeder (2005) for mammals and Gill \& Donsker (2011) for birds.

To test for relationships at the family level we classified a family as carnivorous or herbivorous only if every species in that family for which we have $T_{b}$ data was a carnivore or herbivore. Families that contained omnivores, or included both carnivorous and herbivorous species, we classified as 'mixed'. The frequency distribution of $\mathrm{T}_{\mathrm{b}}$ values within each family was typically skewed, and so we used median $T_{b}$ values to characterise each family; the patterns and statistical conclusions were identical if mean values were used.

Data were analysed with one-way ANOVA and a General Linear Model (GLM) with diet as fixed factor. All statistical analyses were performed using Minitab. To allow for phylogenetic non-independence, we used Phylogenetic Generalised Least Squares Regression (PGLS), assuming trait evolution under Brownian motion $(\kappa=1)$. For mammals we used the species-level supertree updated by Fritz et al. (2009) and for birds we used a set of 100 phylogenies randomly selected from the distribution provided by Jetz et al. (2012) based on the Hackett tree. We used Pagel's $\lambda$ (Pagel 1999) to account for phylogenetic covariance between $\mathrm{T}_{\mathrm{b}}$, diet class and body size. PGLS analyses were performed in R 2.13.2 using the package CAPER.

Details of the $T_{b}$ and body mass data, dietary classification and all statistical analyses are given in Appendix S1.

\section{RESULTS}

\section{Correlation of diet with body temperature}

The mean body temperature of mammals varied significantly between trophic levels: carnivores had the lowest mean $\mathrm{T}_{\mathrm{b}}$, with herbivores and omnivores showing higher, and similar, mean $\mathrm{T}_{\mathrm{b}}$ values (Table 1 ). Although the mean values differ by only $\sim 1 \mathrm{~K}$, the differences between trophic levels were highly significant statistically $\left(\mathrm{F}_{2,425}=14.9, \mathrm{p}<\right.$ 0.001 for Trophic Level 1, $F_{2,425}=17.2, p<0.001$ for Trophic Level 2).

In birds there was a marginally significant variation in mean $\mathrm{T}_{\mathrm{b}}$ across trophic levels $\left(\mathrm{F}_{2,482}=\right.$ $3.41, \mathrm{p}=0.034$ ), driven principally by a high value for omnivores (Table 1 ). When the analysis was repeated with the stricter trophic level classification (Trophic Level 2), the pattern of variation in mean $\mathrm{T}_{\mathrm{b}}$ across trophic levels was similar but statistically much stronger $\left(\mathrm{F}_{2,482}=19.8, \mathrm{p}<0.001\right)$. 
The mean body temperature of mammals varied significantly with Pantheria diet class $\left(\mathrm{F}_{7,425}\right.$ $=12.0, \mathrm{p}<0.001)$. This conclusion was strengthened when the analysis was confined to those six diet classes with data for more than 20 species $\left(F_{5,401}=15.2, p<0.001\right)$. Of the eight diet classes examined, carnivores consuming invertebrate prey had the lowest mean $T_{b}$, and herbivores eating seeds or grass had the highest mean $\mathrm{T}_{\mathrm{b}}$; intriguingly, carnivores taking vertebrate prey also had a high mean $\mathrm{T}_{\mathrm{b}}$. The body temperature of birds also varies with Pantheria diet category $\left(\mathrm{F}_{7,411}=9.08, \mathrm{p}<0.001\right)$, with the highest mean $\mathrm{T}_{\mathrm{b}}$ in herbivores eating grass or seeds, and (in contrast to mammals) carnivores taking invertebrates.

We repeated the analysis using the modified dietary classification of Chivers \& Hladik (1980). In mammals there was a highly significant difference in mean $T_{b}$ between the modified Chivers diet classes $\left(\mathrm{F}_{5,318}=15.8, \mathrm{p}<0.001\right)$, with foliovores and granivores having the highest mean $\mathrm{T}_{\mathrm{b}}$ and frugivores and carnivores taking invertebrates the lowest (Table 2). In birds there was also a significant variation in mean $T_{b}$ across the modified Chivers diet categories $\left(\mathrm{F}_{5,391}=14.5, \mathrm{p}<0.001\right)$, with granivores having the highest mean $\mathrm{T}_{\mathrm{b}}$ and species taking flowers or nectar the lowest (Table 2).

Allowing for the effects of body mass

In both birds and mammals $\mathrm{T}_{\mathrm{b}}$ varies with body mass, $\mathrm{M}_{\mathrm{b}}$, with larger mammals tending to be warmer and larger birds cooler (McNab 1966; White \& Seymour 2003; Clarke \& Rothery 2008). We therefore repeated the analysis using a General Linear Model (GLM) to control for $\mathrm{M}_{\mathrm{b}}$, with trophic level or diet category as a fixed factor.

For mammals there was no indication that the scaling relationship of $\mathrm{T}_{\mathrm{b}}$ with $\mathrm{M}_{\mathrm{b}}$ differed between carnivores, herbivores and omnivores (Trophic Level 2: $F_{2,371}=0.87, p=0.42$ ). After fitting a common slope there were significant differences in elevation $\left(\mathrm{F}_{2,371}=19.5, \mathrm{p}<\right.$ 0.001): herbivores were warmest, carnivores coolest and omnivores intermediate. For the modified Chivers diet classification, the hypothesis of common slope again could not be rejected $\left(\mathrm{F}_{5,274}=2.18, \mathrm{p}=0.056\right)$, and after fitting a common slope there were significant differences in elevation between diet classes $\left(\mathrm{F}_{5,274}=13.8, \mathrm{p}<0.001\right)$. The pattern matched the initial analysis, with the lowest mean $\mathrm{T}_{\mathrm{b}}$ in carnivores taking invertebrates and herbivores taking flowers or nectar, and the highest mean $\mathrm{T}_{\mathrm{b}}$ in herbivores eating foliage or seeds and carnivores taking vertebrate prey (See Appendix S1). Correction for the effects of body mass thus does not change either the pattern or the significance of the variation in mean $T_{b}$ with diet class in mammals.

In birds the GLM indicated that there was significant heterogeneity in the scaling of $\mathrm{T}_{\mathrm{b}}$ on body mass for different trophic levels $\left(\mathrm{F}_{2,452}=14.0, \mathrm{p}<0.001\right)$, and also across the modified Chivers diet categories $\left(\mathrm{F}_{5,361}=4.33, \mathrm{p}<0.001\right)$. The GLM analysis suggested that the pattern of variation of $\mathrm{T}_{\mathrm{b}}$ across trophic levels and modified Chivers diet categories was strikingly similar to that of mammals, but the heterogeneity of slopes makes further interpretation difficult. 
Allowing for phylogenetic non-independence

Because species within families or orders are likely to be similar in physiology and ecology as a result of a shared evolutionary ancestry, the relationship between $T_{b}$ and diet was examined with data pooled at family and order level (see Methods).

A plot of median $T_{b}$ as a function of median $M_{b}$ for mammal families (Figure 1a) showed that in families with median body mass $>50 \mathrm{~g}$, there was a clear tendency for herbivores to exhibit a higher median $\mathrm{T}_{\mathrm{b}}$ than carnivores. For these larger taxa there was only one herbivore family with median $\mathrm{T}_{\mathrm{b}}<35^{\circ} \mathrm{C}$ (Xenarthra, where $\mathrm{T}_{\mathrm{b}}$ is highly labile; $\mathrm{n}=2$ ) and only one carnivore family with a median $\mathrm{T}_{\mathrm{b}}>35^{\circ} \mathrm{C}$ (Felidae, $\mathrm{n}=8$ ). For mammals as a whole carnivorous families have a significantly lower $\mathrm{T}_{\mathrm{b}}$ than herbivores, or families with mixed diets (ANOVA, $\left.\mathrm{F}_{3,100}=8.22, \mathrm{p}<0.001\right)$. There is also significant variation in $\mathrm{T}_{\mathrm{b}}$ across mammalian orders $\left(\mathrm{F}_{24,425}=15.5, \mathrm{p}<0.001\right)$. For those mammalian orders for which we have diet data on ten or more species, the two orders with the highest mean $\mathrm{T}_{\mathrm{b}}$ (Lagomorpha, Artiodactyla) are both purely herbivorous (for details see Appendix S1).

In bird families there was no significant difference in mean family $T_{b}$ between the three diet groups $\left(\mathrm{F}_{2,81}=1.87, \mathrm{p}=0.161\right)$. There was no visual discernible tendency for herbivorous families to have a higher median $\mathrm{T}_{\mathrm{b}}$ (Figure $1 \mathrm{~b}$ ) but most bird orders are dominated by consumers of invertebrates and very few have any herbivorous taxa.

In mammals the phylogenetic signal $(\lambda)$ in the data was strong, but analysis with PGLS indicated a significant relationship between trophic level and $T_{b}$, with herbivores warmer than carnivores, after allowing for the effects of both body mass and phylogenetic nonindependence (Table 3). For the analysis based on modified Chivers diet categories, the pattern of mean $T_{b}$ across diet categories was similar to that of the GLM analysis though the estimated mean $\mathrm{T}_{\mathrm{b}}$ values were lower than those estimated from the GLM (Table 4). For birds the phylogenetic signal was again strong, but here the distribution of $\mathrm{T}_{\mathrm{b}}$ across trophic levels and diet categories was non-significant after allowing for the effects of body mass and phylogenetic non-independence (Table 3).

Relationship between environmental temperature, diet and body temperature

At the species level, carnivores with relatively low $\mathrm{T}_{\mathrm{b}}$ are only found in warmer habitats, and only herbivores are found in the very coldest habitats (Figure 3a). The relationship between diet type and mean ambient temperature within the range is significant (one-way ANOVA with modified Chivers diet category as factor, $\mathrm{F}_{5,288}=7.15, \mathrm{p}<0.001$ ), with foliovores and granivores being associated with the lowest mean environmental temperature, and frugivores the highest (see Appendix S1). The pattern is fairly similar at family level (Figure 3b), and the ten families extending into the coldest habitats are either herbivorous or omnivorous. Whilst there are striking examples of carnivores such as Polar Bears, Ursus maritimus, and Wolves, Canis lupus, extending into the high Arctic, our analyses concern mean values for dietary categories or families.

\section{DISCUSSION}

We have demonstrated a significant tendency for herbivory in mammals to be associated with a high $T_{b}$, and in particular for mean $T_{b}$ to be highest in foliovores. This pattern is robust to 
correction for the effects of body mass and phylogenetic non-independence. There was, however, considerable overlap in the range of $T_{b}$ values for each diet category. This means that a particular species, or a comparison based on a small number of selected taxa, may not fit the broad general pattern we have established. In birds the highest $\mathrm{T}_{\mathrm{b}}$ was found in herbivorous diet categories (foliovores, granivores and frugivores), but the pattern was not significant after allowing for phylogenetic non-independence.

Is there a common pattern across endotherms?

If we are seeking a general relationship between diet and $\mathrm{T}_{\mathrm{b}}$ in endotherms, we should expect the pattern to be similar in mammals and birds. Direct comparison is however complicated by the difference in $T_{b}$ between the two groups: birds exhibit a higher $T_{b}$ than mammals, and the range of individual $\mathrm{T}_{\mathrm{b}}$ values is narrower than in mammals (birds: range $35.0-41.7{ }^{\circ} \mathrm{C}$, interquartile range $1.8 \mathrm{~K}$; mammals: range $30.2-40.7^{\circ} \mathrm{C}$, interquartile range $2.2 \mathrm{~K}$ ).

Fitting ordinary least-squares (OLS) regressions to allow for the effects of body mass indicates a striking commonality in the relation between mean residual $\mathrm{T}_{\mathrm{b}}$ and diet for herbivorous mammals and birds (Figure 2). In both classes, mean $\mathrm{T}_{\mathrm{b}}$ is highest in foliovores and granivores, and lowest in species taking flowers or nectar. This pattern is intriguing, as the mean $T_{b}$ for the different diet categories increases in parallel with the fraction of cellulose in the diet (low in fruit, intermediate in seeds, high in foliage). Although the distribution of residuals across diet classes is highly suggestive of a common pattern across endotherm herbivores, the relationship in birds could not be resolved with a GLM because of the heterogeneity of slopes across diet classes. The residual for carnivores overall is lower than that of foliovores and granivores.

In mammals the residuals show excellent agreement with the mean $T_{b}$ values estimated by both GLM and PGLS analyses (see Appendix S1 for details). A comparison was not possible for birds because the diet/ $T_{b}$ relationship PGLS was not significant in a PGLS analysis.

Is there a general relationship between temperature and herbivory?

If there is a fundamental physiological link between high $\mathrm{T}_{\mathrm{b}}$ and a herbivorous diet, as suggested by our analyses, then we would expect this to be observed in other vertebrate groups. In reptiles an association between high $\mathrm{T}_{\mathrm{b}}$ and herbivory has long been known (Cooper \& Vitt 2002), in both large (Pough 1973) and in small (Espinoza et al. 2004) taxa. Most lizards are carnivorous but comparative studies have shown clearly that whilst carnivorous species can exhibit a wide range of $\mathrm{T}_{\mathrm{b}}$ values, herbivorous lizards generally maintain a narrower range of higher body temperatures (Espinoza et al. 2004).

With the possible exception of some small fruit-eating tropical frogs (for example Xenohyla truncata: da Silva \& de Britto-Pereira 2006), all adult amphibians take invertebrate prey, principally insects (Hillman et al. 2009). Interestingly, herbivory is widespread among larval amphibians (Altig \& Kelly 1974), whose aquatic habitat means that $\mathrm{T}_{\mathrm{b}}$ is likely to be highly variable and difficult to control. Herbivory is also uncommon among fishes, and is most frequent in warmer waters. In temperate marine habitats between 5 and $15 \%$ of species are herbivorous, whereas in coral reef assemblages up to $50 \%$ of the species may be herbivorous (Horn 1989). 
In both reptiles and fish, digestion of plant material appears to be reliant on fermentation by gut microbes (Mountfort et al. 2002; Rimmer \& Weibe 2006). Gaines \& Lubchenco (1982) suggested that the low frequency of herbivory in fishes living at higher latitudes might be caused by temperature constraints on the activity of the gut microflora, and Floeter et al. (2005) concluded that herbivory in marine fishes was only possible above a threshold of $\sim 15^{\circ} \mathrm{C}$. Whilst there is clearly room for more work (Clements et al. 2009), there remains a general consensus that low body temperatures make herbivory energetically unfavourable, in that they constrain the rate at which energy can be extracted from the diet.

The link between herbivory and a high $\mathrm{T}_{\mathrm{b}}$ in reptiles and fish suggests a fundamental ecophysiological relationship evident over broad spatial scales: herbivory becomes common only above a threshold $\mathrm{T}_{\mathrm{b}}$ of $\sim 15^{\circ} \mathrm{C}$. All mammals and birds have $\mathrm{a} \mathrm{T}_{\mathrm{b}}$ that exceeds this threshold (except when torpid or hibernating), but the data we report here indicates that even within endotherms there may be subtle energetic advantages for some classes of herbivores from quite small increases in $\mathrm{T}_{\mathrm{b}}$. In mammals the difference in mean $\mathrm{T}_{\mathrm{b}}$ between carnivores taking invertebrate prey and herbivores consuming grass or leaves is $\sim 2.6 \mathrm{~K}$ (Table 2). In birds the signal is complicated by the strong association between $\mathrm{T}_{\mathrm{b}}$ and body mass, but correction for body mass suggests a similar pattern of difference among dietary groups (Figure 2). These differences are small, but they suggest that the energetic advantages to be gained from having a warmer body when utilising some herbivorous diets outweighs the metabolic costs of maintaining a slightly warmer body.

Whilst the association between some herbivorous diets and a warmer body is clear, the precise physiological mechanism is not. It has long been argued that herbivores require a warmer body to support fermentation by gut microbes, but all digestive processes will proceed faster in warmer bodies (Wang et al. 2002) and many ectotherms select a warmer microenvironment when digesting food (Lang 1979; Petersen et al. 2011). The intriguing question is why the trade-off between enhanced rates of energy acquisition and the associated increased metabolic costs should be at different temperatures for different diets.

Do other factors influence the relationship between diet and body temperature?

Whilst mammals and birds show a significant difference in the mean $T_{b}$ of herbivores and carnivores, there is considerable overlap in the range of $T_{b}$ values for each trophic level. Some of this variability is correlated strongly with phylogeny. For example the high mean $T_{b}$ for mammalian herbivores is driven principally by artiodactyls and lagomorphs, and cats exhibit a high mean $\mathrm{T}_{\mathrm{b}}$ compared with other carnivorous mammals (Clarke \& Rothery 2008). This suggests that other factors, additional to diet, are involved in determining $\mathrm{T}_{\mathrm{b}}$. One of these may be activity level; Lovegrove (2000, 2004) found that in larger mammals (> $500 \mathrm{~g}$ ), a high residual BMR was correlated with cursoriality. Since BMR and $\mathrm{T}_{\mathrm{b}}$ are correlated in mammals (Clarke et al.2010), this would suggest that more cursorial mammals will also have a higher $\mathrm{T}_{\mathrm{b}}$, all other things being equal. Lovegrove (2012) showed that all mammalian lineages with a mean $\mathrm{T}_{\mathrm{b}}>37.9^{\circ} \mathrm{C}$ were highly cursorial. These cursorial lineages included Lagomorpha, Artiodactyla and Carnivora, the three orders with the highest mean $\mathrm{T}_{\mathrm{b}}$ in our analysis (see Appendix S1). This suggests strongly that whilst $\mathrm{T}_{\mathrm{b}}$ is clearly associated with diet in mammals, the picture is complicated by covariation with activity level. 
It has long been recognised that within a data set comprising many different species, the degree of phylogenetic relatedness between the species may be reflected in the degree of similarity in the ecological traits of interest. The influence of phylogeny on ecology means that it is important to frame hypotheses carefully, and then use an appropriate statistical analysis (Harvey \&Pagel 1991; Freckleton 2009; White et al. 2012).

The hypothesis we have tested is explicitly physiological: a herbivorous diet requires a warmer body than carnivory. In testing this hypothesis with conventional analyses (ANOVA, GLM), we are assuming implicitly that phylogeny has a minimal influence on $T_{b}$, and that the primary driver for the pattern of $\mathrm{T}_{\mathrm{b}}$ across species is physiological. This is unlikely to be the case, and so we have also tested a subtly different hypothesis, which is that the distribution of $\mathrm{T}_{\mathrm{b}}$ across species is influenced by both diet and phylogenetic descent. The relationship between diet and body temperature was significant in mammals in a PGLS analysis, but not in birds (Table 3 ).

In both mammals and birds there is strong niche conservation of diet within lineages (orders: see Appendix S1): all artiodactyls and lagomorphs are herbivores, all cats are carnivores, and so on. This strong covariation between diet and phylogeny must be considered in the interpretation of possible causes of the relationship we observe (or not) between diet and body temperature. Do artiodactyls have a high $\mathrm{T}_{\mathrm{b}}$ because they are artiodactyls, or because they are herbivores? For mammals, $\mathrm{T}_{\mathrm{b}}$ explained variation in diet in addition to variation explained by phylogenetic descent, lending support to a potential physiological explanation. In birds, the result was less clear, because the effect of $T_{b}$ was no longer significant after phylogenetic variation was modelled.

An alternate approach to this question is to look for evolutionary reversals, that is an isolated carnivore in a lineage of herbivores, or vice versa. Unfortunately such examples are infrequent in our data set. In mammals only for Rodentia and Chiroptera were there enough taxa with a sufficient range of diets to undertake a test. In Rodentia, the mean $\mathrm{T}_{\mathrm{b}}$ of foliovores $\left(37.1 \pm 1.1^{\circ} \mathrm{C}, \mathrm{n}=50\right)$, frugivores $\left(37.4 \pm 1.3^{\circ} \mathrm{C}, \mathrm{n}=5\right)$ and granivores $(36.4 \pm$ $1.8^{\circ} \mathrm{C}, \mathrm{n}=33$ ) exceeded that of the few predominantly carnivorous taxa taking invertebrate prey $\left(35.8 \pm 1.5^{\circ} \mathrm{C}, \mathrm{n}=3\right)$, but the ANOVA is not quite significant $\left(\mathrm{F}_{3,87}=2.54, \mathrm{p}=0.06\right)$. Among bats (Chiroptera) the ANOVA was significant $\left(\mathrm{F}_{3,53}=4.54, \mathrm{p}=0.031\right)$, driven principally by a high mean $\mathrm{T}_{\mathrm{b}}$ for frugivores $\left(36.4 \pm 1.0^{\circ} \mathrm{C}, \mathrm{n}=22\right)$ in comparison with invertebrate carnivores $\left(34.6 \pm 2.8^{\circ} \mathrm{C}, \mathrm{n}=25\right)$.

In birds only two non-passerine orders show sufficient dietary variation to allow a test, and within neither Anseriformes nor Apodiformes is there significant variation in $\mathrm{T}_{\mathrm{b}}$ across diet categories (all $\mathrm{p}>0.05$ ). The bird data set is dominated by Passeriformes ( 238 of 485 species). When the analysis is confined to passerines, a GLM indicates that whilst herbivores eating foliage had the highest mean $\mathrm{T}_{\mathrm{b}}$ for any diet class, variation across trophic levels and diet categories remains non-significant after controlling for body mass (all $p>0.05$ ).

The strong phylogenetic signal evident in all the PGLS analyses (Table 3) suggests that in both mammals and birds the distribution of $\mathrm{T}_{\mathrm{b}}$ across species has a significant historical element. Lovegrove (2012) has suggested that an increase in mammalian $\mathrm{T}_{\mathrm{b}}$ was associated with global cooling and the change in vegetation following the Palaeocene/Eocene thermal maximum, and specifically the evolution of cursoriality. This hypothesis is independent of 
diet, and may explain why strongly cursorial carnivores exploiting vertebrate prey have a $T_{b}$ approaching that of herbivores such as artiodactyls and lagomorphs, whereas other carnivores have a lower $T_{b}$. Whilst diet does appear to play an important role in influencing $T_{b}$ (Figure $2)$, there are clearly other factors involved.

Is diet related to body temperature or to BMR?

The pattern of $\mathrm{T}_{\mathrm{b}}$ and herbivory across vertebrates in general suggests strongly that utilisation of plant material is associated with a warm body. There is, however, an interesting dichotomy in that ecologists working with reptiles and fish have interpreted diet in terms of $\mathrm{T}_{\mathrm{b}}$ (Pough 1973; Gaines \& Lubchenco 1982; Zimmerman \& Tracy 1989; Cooper \& Vitt 2002; Espinoza et al. 2004), whereas those interested in mammals have generally emphasised the relationship between diet and metabolic rate (McNab 1992, 2008). The resolution of this dichotomy comes through the interdependence of metabolic rate and temperature. In endotherms the main source of heat for maintaining a high $\mathrm{T}_{\mathrm{b}}$ comes from metabolism; at the same time the level of $\mathrm{T}_{\mathrm{b}}$ influences basal metabolic rate (BMR), because it is energetically more expensive to maintain a warm body than a cool one (Clarke et al.2010).

For endotherms although the mean increase in $T_{b}$ in herbivores compared with carnivores is small, this higher $T_{b}$ comes at an energetic cost: a higher $T_{b}$ necessarily leads to a higher BMR (Clarke et al. 2010). The energy required to fuel a higher BMR must be met by a higher energy intake, and the difference is not trivial. For example, based on the mean $T_{b}$ values observed in this study and the temperature sensitivity of BMR in endotherms (Clarke et al. 2010), a 150g foliovore has a predicted BMR higher by $29 \%$ compared with an invertebrate carnivore of similar size.

The extent to which herbivores are warmer must thus reflect a trade-off between the enhanced energy intake from food at a higher $T_{b}$ and the higher metabolic costs following from that $T_{b}$. Additional to the effect of $T_{b}$ on BMR will be a contribution from the energetic costs of differences in gut length, activity level (for example cursoriality), brain size and so on (see for example Williams et al. 2001). Together these lead to a significantly higher BMR in mammalian herbivores than mammalian carnivores, on average. This increased BMR is not of itself an energetic advantage; it represents the cost of maintaining a body adapted to eating a diet containing cellulose. The benefit comes from the greater energy available from plant food at the higher $T_{b}$.

\section{Concluding remarks}

We can therefore propose a general picture for all vertebrates, which is that herbivores consuming plant tissues high in cellulose tend to maintain a higher $\mathrm{T}_{\mathrm{b}}$ than carnivores. This higher $\mathrm{T}_{\mathrm{b}}$ may be generated either through endothermy (mammals, birds), by behavioural thermoregulation (small reptiles) or by living in a warm environment (tropical reptiles and fish). Whilst a high $\mathrm{T}_{\mathrm{b}}$ is a widespread feature of herbivores, it is not universal. For example sloths (Xenarthra) and some temperate fishes are herbivorous despite a lower $T_{b}$.

Overall, the association between herbivory and a high $\mathrm{T}_{\mathrm{b}}$ in vertebrates is highly persuasive, and can be regarded as a useful macrophysiological generalisation (Gaston et al. 2009). This association might suggest that amongst ectotherms, herbivory would exhibit a relationship 
with climate, with herbivory commoner in warmer habitats. This does appear to be the case: the diversity of modern herbivorous insects and the pressure they exert on their plant hosts generally increases towards the tropics (Wilf \& Labandeira 1999; but see also Salazar \& Marquis 2012). Furthermore increases in the extent of insect herbivory can be detected during early Cenozoic warming (Wilf et al. 2001) and during the Palaeocene/Eocene thermal maximum (Currano et al. 2008, 2010). Terrestrial reptiles were important herbivores during the Mesozoic, and many of these achieved a high and stable $\mathrm{T}_{\mathrm{b}}$ through their large size (O’Connor \& Dodson 1999; Eagle et al. 2011; Head et al. 2013).

Despite the associated metabolic costs, herbivory is widespread in mammals, and the incidence of herbivory at class level exceeds that in reptiles, amphibians and fish by a wide margin. Whilst a broadening of the diet cannot of itself have been the initial driving force behind the evolution of endothermy (Clarke \& Pörtner 2010), it may well be one of its most important ecological consequences. The evolution of a permanently warm body allowed an increasing diversity of mammals to utilise a widespread and abundant food resource that was previously the preserve of insects and the large herbivorous dinosaurs, until the latter's demise at the $\mathrm{K} / \mathrm{Pg}$ extinction event.

\section{Acknowledgements}

We thank Ray Huey for much useful advice on reptilian herbivores and stimulating discussion of the problem of herbivory in general. We also thank two anonymous referees for valuable comments that sharpened our thinking in a number of places. This work was undertaken whilst AC was in receipt of an Emeritus Fellowship from the British Antarctic Survey and an honorary position at the University of East Anglia.

\section{References}

Altig, R. \& Kelly, J.P. (1974) Indices of feeding in anuran tadpoles as indicated by gut characteristics. Herpetologica, 30, 200-203.

Chivers, D.J. \& Hladik, C.M. (1980) Morphology of the gastrointestinal tract in primates: comparison with other mammals in relation to diet. Journal of Morphology, 166, 337-386.

Clarke, A. \& Rothery, P. (2008) Scaling of body temperature in birds and mammals. Functional Ecology, 22, 58-67.

Clarke, A., Rothery, P. \& Isaac, N.J.B. (2010) Scaling of basal metabolic rate with body mass and temperature in mammals. Journal of Animal Ecology, 79, 610-619.

Clarke, A. \& Pörtner, H.O. (2010) Temperature, metabolic power and the evolution of endothermy. Biological Reviews, 85, 703-727.

Clements, K.D., Raubenheimer, D. \& Choat, J.H. (2009) Nutritional ecology of marine herbivorous fishes: ten years on. Functional Ecology, 23, 79-92.

Cooper, W.E. \& Vitt, L.J. (2002) Distribution, extent, and evolution of plant consumption by lizards. Journal of Zoology, 257, 487-517.

Currano, E.D., Wilf, P., Wing, S.L., Labandeira, C.C., Lovelock, E.C. \& Royer, D.L. (2008) Sharply increased insect herbivory during the Paleocene-Eocene thermal maximum. Proceedings of the National Academy of Sciences of the United States of America, 105, 1960-1964.

Currano, E.D., Labandeira, C.C. \& Wilf, P. (2010) Fossil insect folivory tracks paleotemperature for six million years. Ecological Monographs, 80, 547-567.

da Silva, H.R. \& de Britto-Pereira, M.C. (2006) How much fruit do fruit-eating frogs eat? An investigation on the diet of Xenohyla truncata (Lissamphibia: Anura: Hylidae). Journal of Zoology, 270, 692-698.

del Hoyo, J., Elliott, A., Sargatal, J. \& Christie, D.A. (ed.^eds) (1992-2011) Handbook of the birds of the world. Lynx Edicions, Barcelona.

Eagle, R.A., Tütken, T., Martin, T.S., Tripati, A.K., Fricke, H.C., Connely, M., Cifelli, R.L. \& Eiler, J.M. 
(2011) Dinosaur body temperatures determined from isotopic $\left({ }^{13} \mathrm{C}-{ }^{18} \mathrm{O}\right)$ ordering in fossil biominerals. Science, 333, 443-445.

Espinoza, R.E., Wiens, J.J. \& Tracy, C.R. (2004) Recurrent evolution of herbivory in small, cold-climate lizards: Breaking the ecophysiological rules of reptilian herbivory. Proceedings of the National Academy of Sciences of the United States of America, 101, 16819-16824.

Floeter, S.R., Behrens, M.D., Ferreira, C.E.L., Paddack, M.J. \& Horn, M.H. (2005) Geographic gradients of marine herbivorous fishes: patterns and processes. Marine Biology, 147, 1435-1447.

Freckleton, R.P. (2009) The seven deadly sins of comparative analysis. Journal of Evolutionary Biology, 22, 1367-1375.

Fritz, S.A., Bininda-Emonds, O.R.P. \& Purvis, A. (2009) Geographical variation in predictors of mammalian extinction risk: big is bad, but only in the tropics. Ecology Letters, 12, 538-549.

Gaines, S.D. \& Lubchenco, J. (1982) A unified approach to marine plant-herbivore interactions. 2. Biogeography. Annual Review of Ecology and Systematics, 13, 111-138.

Gaston, K.J., Chown, S.L., Calosi, P., Bernardo, J., Bilton, D.T., Clarke, A., Clusella-Trullas, S., Ghalambor, C.K., Konarzewski, M., Peck, L.S., Porter, W.P., Pörtner, H.O., Rezende, E.L., Schulte, P.M., Stillman, J.H., Terblanche, J.S. \& van Kleunen, M. (2009) Macrophysiology: a conceptual re-unification. American Naturalist, 174, 595-612.

Gill, F. \& Donsker, D. (2011) IOC World Bird Names (version 2.10). Available at http://www.worldbirdnames.org/ [Accessed 15 April 2012]. Available at: (accessed

Glazier, D.S. (2005) Beyond the '3/4-power law': variation in the intra- and interspecific scaling of metabolic rate in animals. Biological Reviews, 80, 611-662.

Harvey, P.H. \& Pagel, M.D. (1991) The comparative method in evolutionary biology. Oxford University Press, Oxford.

Head, J., Gunnell, G.F., Holroyd, P.A., Hutchinson, J.H. \& Ciochon, R.L. (2013) Giant lizards occupied herbivorous mammalian ecospace during the Paleogene greenhouse in Southeast Asia. Proceedings of the Royal Society of London, Series B, 280, Published on-line 5 June 2013.

Heusner, A.A. (1985) Body size and energy metabolism. Annual Review of Nutrition, 5, 267-293.

Hillman, S.S., Withers, P.C., Drewes, R.C. \& Hillyard, S.D. (2009) Ecological and environmental physiology of amphibians. Oxford University Press, Oxford.

Horn, M.H. (1989) Biology of marine herbivorous fishes. Oceanography and Marine Biology: an Annual Review, 27, 167-272.

Jetz, W., Thomas, G.H., Joy, J.B., Hartmann, K. \& Mooers, A.O. (2012) The global distribution of birds in space and time. Nature, 491, 444-448.

Jones, K.E., Bielby, J., Cardillo, M., Fritz, S.A., O'Dell, J., Orme, C.D.L., Safi, K., Sechrest, W., Boakes, E.H., Carbone, C., Connolly, C., Cutts, M.J., Foster, J.K., Grenyer, R., Habib, M., Plaster, C.A., Price, S.A., Rigby, E.A., Rist, J., Teacher, A., Bininda-Emonds, O.R.P., Gittleman, J.L., Mace, G.M. \& Purvis, A. (2009) PanTHERIA: a species-level database of life-history, ecology, and geography of extant and recently extinct mammals. Ecology, 30, 2648 only.

Karasov, W.H., Martínez del Rio, C. \& Caviedes-Vidal, E. (2011) Ecological diversity of diet and digestive systems. Annual Review of Physiology, 73, 69-93.

Lang, J.W. (1979) Thermophilic response of the American alligator and the American crocodile to feeding. Copeia, 1979, 48-59.

Lovegrove, B.G. (2000) The zoogeography of mammalian basal metabolic rate. American Naturalist, 156, 201219.

Lovegrove, B.G. (2003) The influence of climate on the basal metabolic rate of small mammals: a slow-fast metabolic continuum. Journal of Comparative Physiology B, 173, 87-112.

Lovegrove, B.G. (2004) Locomotor mode, maximum running speed, and basal metabolic rate in placental mammals. Physiological and Biochemical Zoology, 77, 916-928.

Lovegrove, B.G. (2012) The evolution of mammalian body temperature: the Cenozoic supraendothermic pulses. Journal of Comparative Physiology, B, 182, 579-589.

McNab, B.K. (1966) An analysis of the body temperature of birds. Condor, 68, 47-55.

McNab, B.K. (1992) A statistical analysis of mammalian rates of metabolism. Functional Ecology, 6, 672-679.

McNab, B.K. (2008) An analysis of the factors that influence the level and scaling of mammalian BMR. Comparative Biochemistry and Physiology, Part A, 151, 5-28.

Mountfort, D.O., Campbell, J. \& Clements, K.D. (2002) Hindgut fermentation in three species of marine herbivorous fish. Applied and Environmental Microbiology, 68, 1374-1380.

O'Connor, M.P. \& Dodson, P. (1999) Biophysical constraints on the thermal ecology of dinosaurs. Paleobiology, 25, 341-368.

Pagel, M. (1999) Inferring the historical patterns of biological evolution. Nature, 401, 877-884.

Petersen, A.M., Chin, W., Feilich, K.L., Jung, G., Quist, J.L., Wang, J. \& Ellerby, D.J. (2011) Leeches run cold, 
then hot. Biology Letters, 7, 941-943.

Pough, F.H. (1973) Lizard energetics and diet. Ecology, 54, 837-844.

Rimmer, D.W. \& Weibe, W.J. (2006) Fermentative microbial digestion in herbivorous fishes. Journal of Fish Biology, 31, 229-236.

Salazar, D. \& Marquis, R.J. (2012) Herbivore pressure increases toward the equator. Proceedings of the National Academy of Sciences of the United States of America, 109, 12616-12620.

Speakman, J.R. (2000) The cost of living: field metabolic rates of small mammals. Advances in Ecological Research, 30, 177-297.

Wang, T., Zaar, M., Arvedsen, S., Vedel-Smith, C. \& Overgaard, J. (2002) Effects of temperature on the metabolic response to feeding in Python molurus. Comparative Biochemistry and Physiology Part A, 133, 519-527.

White, C.R. \& Seymour, R.S. (2003) Mammalian basal metabolic rate is proportional to body mass ${ }^{2 / 3}$. Proceedings of the National Academy of Sciences of the United States of America, 100, 4046-4049.

White, C.R. \& Seymour, R.S. (2004) Does basal metabolic rate contain a useful signal? Mammalian BMR allometry and correlations with a selection of physiological, ecological, and life-history variables. Physiological and Biochemical Zoology, 77, 929-941.

White, C.R. \& Seymour, R.S. (2005) Sample size and mass range effects on the allometric exponent of basal metabolic rate. Comparative Biochemistry and Physiology Part A, 142, 74-78.

White, E.P., Xiao, X., Isaac, N.J.B. \& Sibly, R.M. (2012) Methodological tools. Metabolic ecology: a scaling approach (ed. by R.M. Sibly, J.H. Brown and A. Kodric-Brown), pp. 9-20. Wiley-Blackwell, Oxford.

Wilf, P. \& Labandeira, C.C. (1999) Response of plant-insect associations to Paleocene-Eocene warming. Science, 284, 2153-2156.

Wilf, P., Labandeira, C.C., Johnson, K.R., Coley, P.D. \& Cutter, A.D. (2001) Insect herbivory, plant defense, and early Cenozoic climate change. Proceedings of the National Academy of Sciences of the United States of America, 98, 6221-6226.

Williams, T.M., Haun, J., Davis, R.W., Fuiman, L.A. \& Kohin, S. (2001) A killer appetite: metabolic consequences of carnivory in marine mammals. Comparative Biochemistry and Physiology Part A, 129, 785-796.

Wilson, D.E. \& Reeder, D.M. (ed.^eds) (2005) Mammal species of the world. A taxonomic and geographic reference (3rd edition), 3rd edn. Johns Hopkins University Press, Baltimore, Maryland.

Zimmerman, L.C. \& Tracy, C.R. (1989) Interactions between the environment and ectothermy and herbivory in reptiles. Physiological Zoology, 62, 374-409.

\section{Biosketches}

Andrew Clarke is interested in the relationship between temperature, physiology and ecology.

Mary O'Connor studies how temperature affects trophic interactions and community structure. 
Table 1. Mean body temperature, $\mathrm{T}_{\mathrm{b}}\left({ }^{\circ} \mathrm{C}\right)$, for mammals and birds in different trophic levels. The two trophic level classifications differ in the strictness of definition of carnivore and herbivore in taxa which switch diet seasonally. Data are uncorrected for body mass.

\begin{tabular}{|c|c|c|c|c|c|c|}
\hline \multirow{2}{*}{ Trophic level } & \multicolumn{3}{|c|}{ Mammal $\mathbf{T}_{b}$} & \multicolumn{3}{|c|}{ Bird $\mathbf{T}_{b}$} \\
\hline & Mean & SD & $\mathbf{n}$ & Mean & SD & $\mathbf{n}$ \\
\hline \multicolumn{7}{|c|}{ Trophic level classification 1} \\
\hline \begin{tabular}{l|l} 
Carnivore \\
\end{tabular} & 35.7 & 2.39 & 156 & 41.3 & 1.32 & 345 \\
\hline Herbivore & 36.8 & 1.59 & 197 & 41.3 & 1.54 & 96 \\
\hline \begin{tabular}{l|l} 
Omnivore \\
\end{tabular} & 36.8 & 1.23 & 73 & 41.9 & 1.25 & 44 \\
\hline \multicolumn{7}{|c|}{ Trophic level classification 2} \\
\hline \begin{tabular}{l|l} 
& Carnivore \\
\end{tabular} & 35.5 & 2.54 & 109 & 41.2 & 1.32 & 295 \\
\hline Herbivore & 36.8 & 1.53 & 156 & 41.0 & 1.84 & 55 \\
\hline Omnivore & 36.6 & 1.61 & 161 & 42.0 & 1.00 & 135 \\
\hline
\end{tabular}

Table 2. Mean body temperature, $\mathrm{T}_{\mathrm{b}}\left({ }^{\circ} \mathrm{C}\right)$, for mammals and birds in different diet categories, using a modified version of the diet classification of Chivers \& Hladik (1980). Data are shown in italics where there were data for fewer than 10 species in that diet class. Data are uncorrected for body mass.

\begin{tabular}{|c|c|c|c|c|c|c|}
\hline \multirow{2}{*}{ Diet class } & \multicolumn{3}{|c|}{ Mammal $\mathbf{T}_{b}$} & \multicolumn{3}{|c|}{$\operatorname{Bird} \mathbf{T}_{b}$} \\
\hline & Mean & SD & n & Mean & SD & $\mathbf{n}$ \\
\hline \multicolumn{7}{|l|}{ Carnivores } \\
\hline \begin{tabular}{l|l} 
Vertebrate prey \\
\end{tabular} & 37.1 & 2.70 & 22 & 40.4 & 1.02 & 62 \\
\hline \begin{tabular}{l|l} 
Invertebrate prey \\
\end{tabular} & 35.0 & 2.01 & 94 & 41.4 & 1.31 & 247 \\
\hline \multicolumn{7}{|l|}{ Herbivores } \\
\hline \begin{tabular}{l|l|} 
& Fruit \\
\end{tabular} & 36.4 & 1.11 & 43 & 41.3 & 1.85 & 3 \\
\hline Foliage (grass or leaves) & 37.3 & 1.38 & 81 & 41.3 & 0.65 & 15 \\
\hline Seeds & 36.4 & 1.84 & 31 & 42.0 & 1.00 & 48 \\
\hline Flowers or nectar & 34.7 & 0.54 & 5 & 39.8 & 2.12 & 22 \\
\hline
\end{tabular}


Table 3. Phylogenetic generalised least-squares (PGLS) regression analysis of relationship between diet and $\mathrm{T}_{\mathrm{b}}$ in mammals, with significance of variation across trophic levels or modified Chivers \& Hladik (1980) diet categories. TroL2: trophic level 2 diet classes, $\lambda$ : phylogenetic signal (maximum likelihood estimate), F: variance ratio, df: degrees of freedom, p: probability. For birds the data for $\lambda$ and $F$ are given as mean with $95 \%$ confidence intervals in parentheses for 100 phylogenies randomly selected from the distribution provided by Jetz et al. 2012.

\begin{tabular}{|c|c|c|c|c|}
\hline Diet classification & $\lambda$ & $\mathbf{F}$ & df & $\mathbf{p}$ \\
\hline \multicolumn{5}{|l|}{ Mammals } \\
\hline \begin{tabular}{l|l} 
& TroL2 \\
\end{tabular} & 0.85 & 4.78 & 4,366 & $<0.001$ \\
\hline \begin{tabular}{l|l} 
& Modified Chivers \\
\end{tabular} & 0.770 & 3.60 & 7,266 & 0.001 \\
\hline \multicolumn{5}{|l|}{ Birds } \\
\hline \begin{tabular}{l|l} 
& TroL2 \\
\end{tabular} & $0.87(0.83,0.91)$ & $1.00(0.54,1.47)$ & 4,454 & $(\mathrm{allp}>0.21)$ \\
\hline Modified Chivers & $0.83(0.78,0.88)$ & $0.87(0.68,1.01)$ & 7,366 & $($ all $p>0.42)$ \\
\hline
\end{tabular}

Table 4. Body temperature estimated for a representative mammal (body mass $150 \mathrm{~g}$ ) and a representative bird (body mass $50 \mathrm{~g}$ ) utilising different diets. $\mathrm{T}_{\mathrm{b}}$ values estimated both from a GLM (allowing for body mass) and PGLS (allowing for both body mass and phylogeny). For birds the estimates were based on mean data from 100 phylogenies analysed. Representative body mass values were rounded values for the median body mass of all mammals or all birds in our data set. Note that in birds the PGLS analysis was non-significant and hence a single $\mathrm{T}_{\mathrm{b}}$ is estimated for all diet categories.

\begin{tabular}{|c|c|c|c|}
\hline & \multirow{2}{*}{ Diet category (modified Chivers) } & \multicolumn{2}{|c|}{$\mathbf{T}_{\mathrm{b}}\left({ }^{\mathbf{0}} \mathrm{C}\right)$} \\
\hline & & GLM & PGLS \\
\hline \multicolumn{4}{|c|}{ Mammal (150g body mass) } \\
\hline & Foliovore & 37.2 & 35.4 \\
\hline & Granivore & 36.4 & 35.1 \\
\hline & Frugivore & 36.4 & 34.9 \\
\hline & Flowers/nectar & 34.8 & 34.0 \\
\hline & Carnivore (vertebrate prey) & 36.5 & 34.5 \\
\hline & Carnivore (invertebrate prey & 35.0 & 33.8 \\
\hline \multicolumn{4}{|c|}{ Bird (50g body mass $)$} \\
\hline & Foliovore & 42.3 & $(41.3)$ \\
\hline & Granivore & 42.1 & $(41.3)$ \\
\hline & Frugivore & 42.2 & $(41.3)$ \\
\hline & Flowers/nectar & 39.6 & $(41.3)$ \\
\hline & Carnivore (vertebrate prey) & 41.2 & $(41.3)$ \\
\hline & Carnivore (invertebrate prey) & 41.5 & $(41.3)$ \\
\hline
\end{tabular}




\section{Figures}

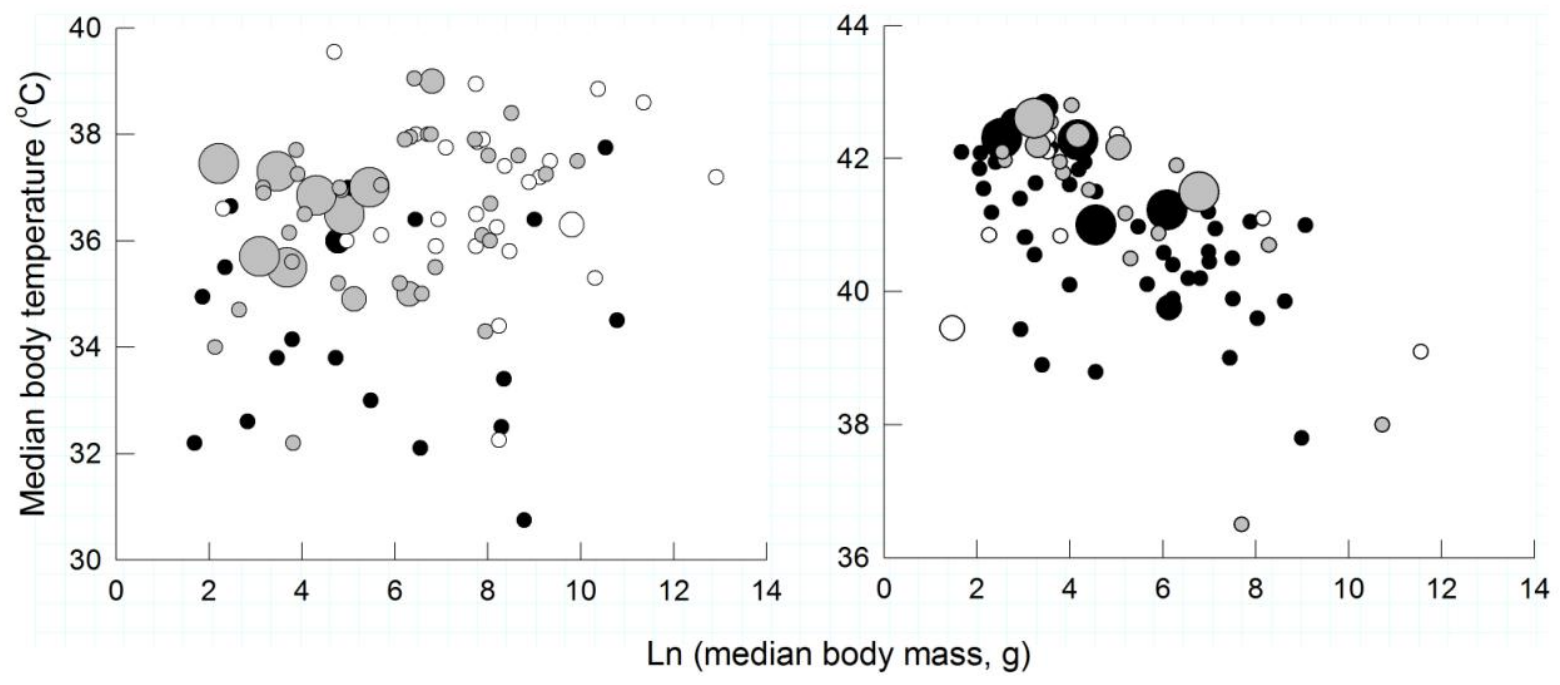

Figure 1. Relationship between median body temperature, $T_{b}\left({ }^{\circ} \mathrm{C}\right)$, and median body mass (g, natural $\log$ transformed) of endotherm families. Families classified into carnivores (black symbols), herbivores (white symbols) and mixed or omnivorous families (grey symbols), with size indicating the number of species within each family for which we have both dietary and $T_{b}$ data: $<10$ taxa (small symbols), 10-19 taxa (medium symbols) and 20+ taxa (large symbols). A (left panel): Mammals. B (right panel): Birds.

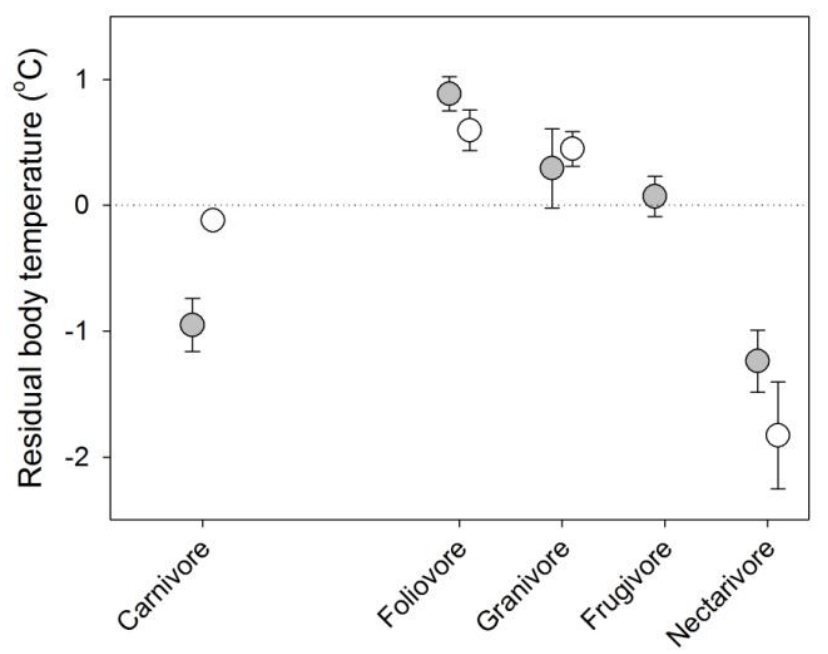

Figure 2. Mean residual body temperature in mammals (grey symbols) and birds (white symbols) for different diet types. Residuals are for OLS regression of $\mathrm{T}_{\mathrm{b}}$ on body mass ( $\mathrm{g}$, natural log transformed). Data are mean \pm SE. Data plotted only for diet categories with data for 5 or more species (range 5 to 237). 

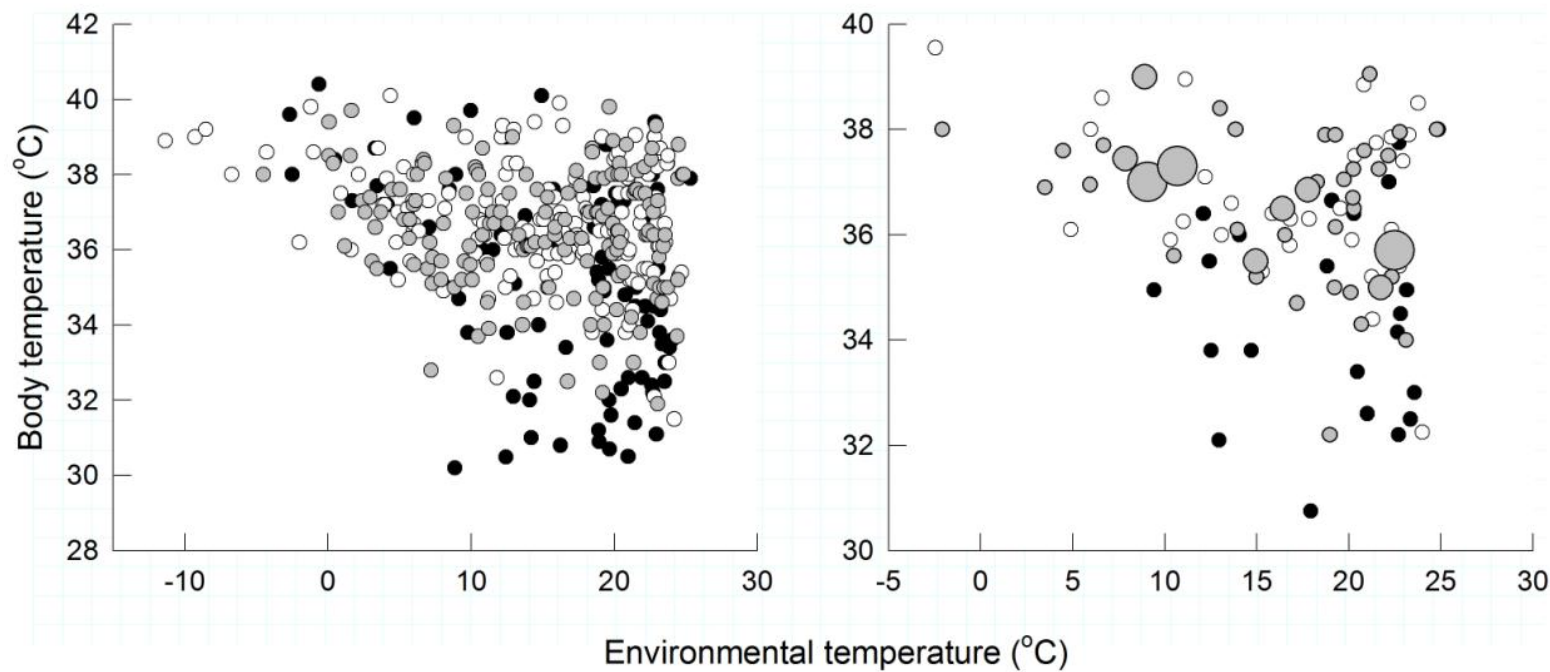

Figure 3. Body temperature and ambient temperature in mammals. A (left panel): Data for individual species, classified by trophic level (herbivores: white symbols, Omnivores: grey symbols, carnivores: black symbols). B (right panel): Data pooled by family. Environmental temperature is the mean temperature over the geographical range of a given species (left panel), or median value for those species of a family represented in the data (right panel). Families classified into carnivores (black symbols), herbivores (white symbols) and mixed or omnivorous families (grey symbols), with size indicating the number of species within each family for which have both dietary and $\mathrm{T}_{\mathrm{b}}$ data: $<10$ taxa (small symbols), 10-19 taxa (medium symbols) and 20+ taxa (large symbols). 